IRA-International Journal of Management \&

Social Sciences

ISSN 2455-2267; Vol.15, Issue 01 (April, 2019)

Pg. no. 7-15.

Institute of Research Advances

http://research-advances.org/index.php/RAJMSS

\title{
Mapping Medical Aspirants Stress Levels Based on Student Versus Parent Led Career Choice- Special Reference to Kota
}

\author{
Prof. D.S. Chundawat ${ }^{1}$ \& Charu Ranawat ${ }^{2 \#}$ \\ ${ }^{1}$ Former Head (Deptt. Of Business Administration), Former Dean (UCCMS), and Former Director \\ (MHRM), UCCMS, ML Sukhadia University, Udaipur, India. \\ ${ }^{2}$ Research Scholar, Department of Business Administration, UCCMS, ML Sukhadia University, \\ Udaipur, India.
}

\# corresponding author

Type of Work: Peer Reviewed.

DOl: http://dx.doi.org/10.21013/jmss.v15.n1.p2

\section{How to cite this paper:}

Chundawat, D.S., Ranawat, C. (2019). Mapping Medical Aspirants Stress Levels Based on Student Versus Parent Led Career Choice- Special Reference to Kota. IRA-International Journal of Management \& Social Sciences (ISSN 2455-2267), 15(1), 7-15. doi:http://dx.doi.org/10.21013/jmss.v15.n1.p2

\section{(C) Institute of Research Advances.}

\section{(cc)) EY-NC}

This work is licensed under a Creative Commons Attribution-Non Commercial 4.0 International License subject to a proper citation to the publication source of the work.

Disclaimer: The scholarly papers as reviewed and published by the Institute of Research Advances (IRA) are the views and opinions of their respective authors and are not the views or opinions of the IRA. The IRA disclaims of any harm or loss caused due to the published content to any party.

Institute of Research Advances is an institutional publisher member of Publishers International Linking Association Inc. (PILA-CrossRef), USA. The institute is an institutional signatory to the Budapest Open Access Initiative, Hungary advocating the open access of scientific and scholarly knowledge. The Institute is a registered content provider under Open Access Initiative Protocol for Metadata Harvesting (OAI-PMH).

The journal is indexed \& included in WorldCat Discovery Service (USA), CrossRef Metadata Search (USA), WorldCat (USA), OCLC (USA), Open J-Gate (India), EZB (Germany) Scilit (Switzerland), Airiti (China), Bielefeld Academic Search Engine (BASE) of Bielefeld University, Germany, PKP Index of Simon Fraser University, Canada. 


\begin{abstract}
This study was conducted to find varying stress levels feel by medical aspirants if they choose to prepare under parental pressure vis-à-vis under their own will considering the amount of hard work and perseverance required to put in for medical entrance in India. Suicide cases and various studies on stress levels among aspiring students, coming from different parts of India to Kota, preparing for medical and engineering entrance examinations make Kota an appropriate and obvious choice for the study. Responses were tabulated using frequency distribution tables and results were derived applying t-test, factor analysis and ANOVA using SPSS version 19. The study concluded that students chose to prepare for medical entrance out of their own will and male medical aspirants feel more stress as compared to female aspirants. Mapping overall stress with the parental pressure have some discrepancies with the previous studies performed by researchers and research institutes which might have caused due to various limitations, one would be a time of the study. This might further be analysed and verify the results as with the change in the social matrix of the social things tend to vary.
\end{abstract}

Keywords: Stress, medical aspirants, adolescence, parental pressure

\title{
Introduction
}

Stress of studies among undergraduate and graduate students is a well-known phenomenon (Bedewy \& Gabriel, 2015) but among various professions medical profession is considered one of the most difficult one across the world due to the extensive curriculum (Madhyastha et al., 2014) and the amount of responsibility of human lives involved in the profession (Malatskey et al., 2017). This stress is even more before entering the medical profession while students prepare for entrance examinations especially in India with so much tough competition and limited medical seats (Sarkar et al., 2017). Sarkar et al. (2017) in their study explained the difference between the selection criterion of medical students in India and in Western countries. Here in India single entrance exam decides score and rank of the aspirants while in Western countries apart from curricular records extracurricular activities, personal research work and voluntary social services carried out, personal interviews etc. contribute to the final selection in medical. This assessment on the basis of a single exam creates a lot of stress amongst the aspirants along with the influence of parents and family (Panchu et al., 2017) for selecting the career.

\section{Literature Summary}

Sarkar et al. (2017) in their study already mentioned about the one-track medical selection process in India which only focusses for marks obtained in that entrance exam put a lot of pressure on students and above that aspiration of parents. in addition to academic and family pressures, there is one more stress given name as uncertainty stress by Wu et al. (2018) which many times not only disturbs students but also lead to self-harm like suicidal attempt especially in the medical profession. Abdulghani et al. (2011) discussed the academic pressures and race to reach among the top rankers lead to competition among the students rather than cooperation between learners which brings on stress and emotional trouble. Daraei (2013)explicitly explained that at the adolescent age when students need to settle down in their life by opting any of the professional course or looking for employability they normally encounter a lot of stress due to expectations from family and society which have a lot of impact on their psychological health. Being a future of any nation, these issues need to be handled carefully. Wu et al. (2018) talk about social capital which means a social network of the stressed persons which can help them to get away from that stress by sharing and venting out their emotional turmoil.

\section{Research Methodology}

The need for the study

Majority of parents in India dream to see their children as doctors, as medicine is considered one of the most prestigious profession. Somehow in Indian societal fabric parents play a key role in determining the career of their children. Under parental pressure at times, children opt for medicine (Prajapati \& Singh, 2015) but preparing for it, is not everybody's cup of tea. The trend to send their children to Kota away from home for the rigorous medical preparation is taking a toll on the mental health of the aspiring students and need to get addressed.

\section{Scope of the study}

This study was carried out in Landmark City of Kota, which is presently a big centre of medical coaching institute Allen. Allen Career Institute, Kota, has a prestigious track record of selections in various medical 
entrance exams pan India including NEET (National Eligibility cum Entrance Test), AIIMS etc (NEET-UG / AIIMS Coaching, n.d.). Students from distant places in India like North East, Bihar, Jharkhand, Odisha, Tamilnadu, Kerala etc. come to Kota especially to get enrolled in Allen to prepare for medical entrance exams. They live for full one year in private hostels away from their families against all the odds. This study would help to know how stressed medical aspirants living in Kota feel and to what extent that stress is driven by parental pressure. The study would also reflect the trend and influence in preparing for medicine as a career across India as students across length and breadth of India are living in Landmark City, Kota.

\section{Time of the Study}

It was the first week of November 2018 when primary data have been collected. This was the time when forms of various medical entrance exams started filling and students living in Landmark City were facing midterm of the year. Along with that during that period most of the students have gone to their homes as Allen has announced Diwali break for ten days.

\section{Significance of the Study}

The increasing stress and suicide cases in Kota lead to State machinery to act upon and appoint TISS (Tata Institute of Social Science) Mumbai, to analyse the increasing suicides by aspiring students in Kota concluded that Kota is not a place for all the students. Not everybody can adjust in that lonely and competitive environment (Chhapia, 2018, January 28). Parents should not force their kids to aspire for medicine if they are not very keen to pursue that. This study would help to understand the share of parental pressure in the overall stress felt by aspiring medical students while preparing under fierce competition where there is no scope of true friends and may help to figure out how free adolescent children are to choose their career.

\section{Contribution of the Study}

The results of the present study could further be used to study the psychological and mental well-being of the medical aspirants in general and specifically in Kota city which was in news since last few years for stress, suicides (Prajapati \& Singh, 2015) and psychological torture amongst our future medical practitioners along with other professional aspirants.

\section{Research Questions}

$>$ What influence students to aspire for medicine?

$>$ Do they feel more stressed if choose to prepare for medical entrance under parental pressure?

\section{Objectives of the Study}

$>$ To know the freedom of choice students, have, to aspire for medicine as a career choice.

$>$ Level of stress feels by students if choose to prepare for medical entrance out of their own choice versus under parental pressure.

\section{Hypotheses}

Parents have an influence on students to aspire for career in medicine.

$>$ Medical aspirants with high parental pressure feel high stress compared to those with low parental pressure

\section{Research Design}

It is descriptive research. A mixed approach of primary data collection was applied. Self- made questionnaires for aspiring students and personal interviews of hostel owners and managers were taken. The population contains students studying in Allen Career Institute, Landmark City, Kunhadi, Kota. The sample survey was conducted where 100 responses were collected through convenience sampling.

\section{Statistical Analysis}

t-test, factor analysis and ANOVA were the applied statistical tools and the Statistical Package for Social Sciences version 19 was the software used for the analysis. 


\section{Results}

Out of 100 respondents out of which 52 were males and 48 were females with the majority of students 18 years old with one attempt given followed by 17 and 16 years and few even older. Table 1 and Table 2 show that distribution.

Table 1: Distribution of respondents according to age

\begin{tabular}{|c|c|c|}
\hline Age & N & Percentage \\
\hline 16 Years & 7 & 7.00 \\
\hline 17 Years & 30 & 30.00 \\
\hline 18 Years & 52 & 52.00 \\
\hline 19 Years & 8 & 8.00 \\
\hline 20 Years & 2 & 2.00 \\
\hline 21 Years & 1 & 1.00 \\
\hline Total & $\mathbf{1 0 0}$ & $\mathbf{1 0 0 . 0 0}$ \\
\hline
\end{tabular}

Table 2: Number of attempts already taken for this exam

\begin{tabular}{|c|c|c|}
\hline Number of attempts & N & Percentage \\
\hline 0 & 2 & 2.00 \\
\hline 1 & 54 & 54.00 \\
\hline 2 & 6 & 6.00 \\
\hline 3 & 0 & 0.00 \\
\hline 4 & 1 & 1.00 \\
\hline No Response & 37 & 37.00 \\
\hline Total & $\mathbf{1 0 0}$ & $\mathbf{1 0 0 . 0 0}$ \\
\hline
\end{tabular}

The sample included students from 17 different states ranging from Assam, Tripura in East, Jammu \& Kashmir in North, Maharashtra and Orissa towards South-East, to even Nepal, as shown in Table 3.

Table 3: Belongs to Which State

\begin{tabular}{|l|c|c|}
\hline \multicolumn{1}{|c|}{ City Name } & N & Percentage \\
\hline Assam & 6 & 6.00 \\
\hline Bihar & 30 & 30.00 \\
\hline Chhattisgarh & 4 & 4.00 \\
\hline Delhi & 2 & 2.00 \\
\hline Jammu \& Kashmir & 4 & 4.00 \\
\hline Jharkhand & 9 & 9.00 \\
\hline Maharashtra & 5 & 5.00 \\
\hline Manipur & 1 & 1.00 \\
\hline MP & 2 & 2.00 \\
\hline
\end{tabular}


IRA-International Journal of Management छั Social Sciences

\begin{tabular}{|l|c|c|}
\hline Nepal & 1 & 1.00 \\
\hline Orissa & 12 & 12.00 \\
\hline Punjab & 1 & 1.00 \\
\hline Rajasthan & 1 & 1.00 \\
\hline Tripura & 1 & 1.00 \\
\hline UP & 15 & 15.00 \\
\hline Uttarakhand Total & 2 & 2.00 \\
\hline West Bengal & 4 & 4.00 \\
\hline
\end{tabular}

Table 4.shows socioeconomic background of the respondents which shows more than fifty per cent were from service background which itself say it all that students would face pressure as they don't have any backup for their future earnings.

Table 4: Distribution of respondents according to the father's profession

\begin{tabular}{|c|c|c|}
\hline Father's Profession & $\mathbf{N}$ & Percentage \\
\hline Service & 52 & 52.00 \\
\hline Business & 25 & 25.00 \\
\hline Self-employed & 6 & 6.00 \\
\hline Others & 17 & 17.00 \\
\hline Total & 100 & 100.00 \\
\hline
\end{tabular}

Table 5. shows factors extracted after applying factor analysis for reasons behind aspiration for medicine as a career. These factors were classified as fascinated by the medical profession, own will to choose the medical profession, and motivated by external influence. Table 6 . shows that majority of students aspired for a career in medicine out of their own will and this factor was significantly higher than other factors $(\mathrm{F}=60.81, \mathrm{p}<0.001)$ with a mean score of 0.68 . The results reveal that first hypothesis falls flat as results show students are deciding on their own about medical as a career thus our first hypothesis, "Parents have an influence on students to aspire for a career in medicine" does not get accepted.

Table 5: Reasons behind aspiration for medicine as a career - factorized

\begin{tabular}{|l|l|}
\hline \multirow{2}{*}{ Factor } & Statement \\
\hline \multirow{4}{*}{ Own will to aspire for the medical profession } & Wedicine is a noble profession \\
\cline { 2 - 2 } & Doctors enjoy the good economic status \\
\cline { 2 - 2 } & Doctors are highly recognized in the society \\
\hline \multirow{4}{*}{ Motivated by external influence } & I wanted to become a doctor \\
\hline & Teacher(s) suggested me \\
\cline { 2 - 2 } & My Parent(s) is/are doctor \\
\cline { 2 - 2 } & My friends also have chosen this profession \\
\cline { 2 - 2 } & My parents wanted me to choose medicine \\
\cline { 2 - 2 } & Inspired by somebody who is a doctor \\
\cline { 2 - 2 } & My siblings/cousins are a doctor \\
\hline
\end{tabular}


Table 6: Factors behind aspiration for medicine as a career

\begin{tabular}{|l|l|l|l|l|c|}
\hline Factor & N & Mean & SD & Rank & F \\
\hline Fascinated by medical profession & 100 & 0.520 & 0.22 & 2 & \\
\cline { 1 - 3 } $\begin{array}{l}\text { Own will to aspire for the medical } \\
\text { profession }\end{array}$ & 100 & 0.680 & 0.43 & 1 & $\begin{array}{c}60.81 \\
(\mathrm{p}<0.001)\end{array}$ \\
\cline { 1 - 4 } Motivated by external influence & 100 & 0.157 & 0.35 & 3 & \\
\hline
\end{tabular}

SD- Standard Deviation

Graph1: Factors behind aspiration for medicine as a career

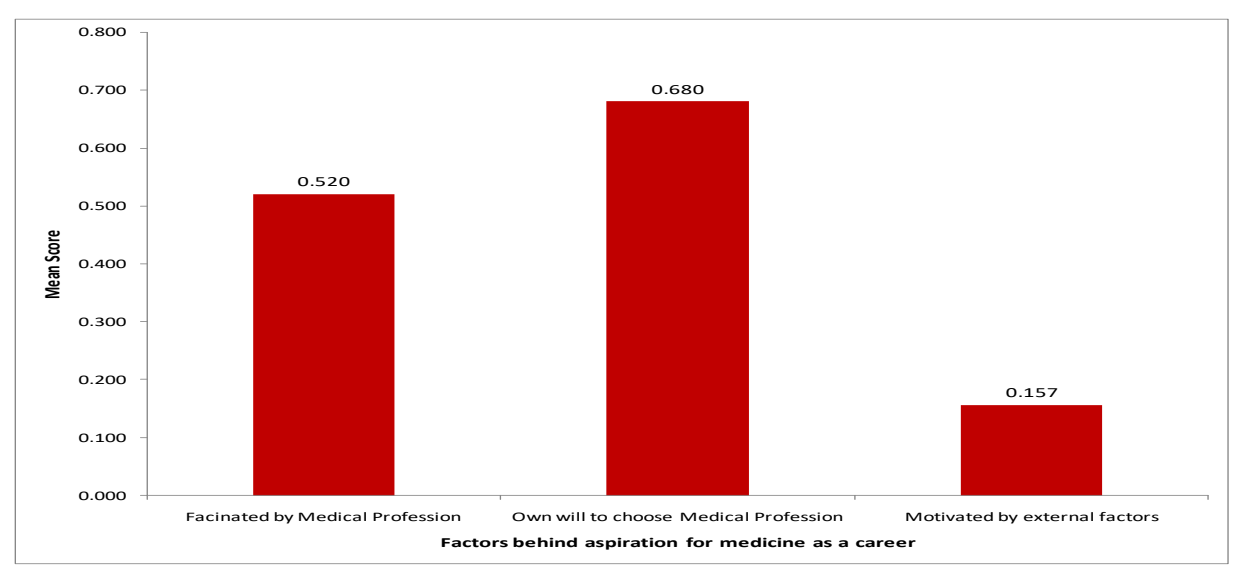

Table 7 shows the comparison of the pressure of studies felt by males and females' respondents. t-test was applied and was found that mean value for males was significantly $(t=2.46, p<0.05)$ higher $(5.65)$ as compared to females (4.40).

Table 7: Pressure of studies compared to male and female respondents

\begin{tabular}{|l|l|l|l|l|l|l|}
\hline Gender & N & Mean & SD & t & df & Result \\
\hline Male & 51 & 5.65 & 2.54 & 2.46 & 94 & $*$ \\
\cline { 1 - 6 } Female & 45 & 4.40 & 2.40 & & \multirow{2}{*}{2.46} \\
\hline
\end{tabular}

SD- standard Deviation df- degree of freedom

Graph 2: Pressure of studies compared to male and female respondents

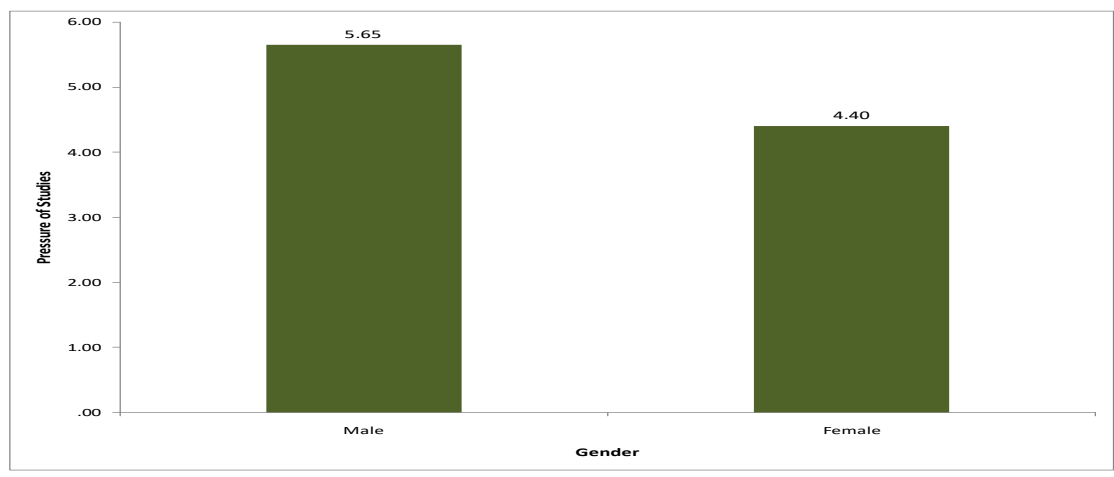

A significant relation between parental pressure and overall stress on medical aspirant was found $(\mathrm{F}=4.23$, $\mathrm{p}<0.05)$. Test results given above show those students with moderate parental pressure found to have high-stress levels as compared to other groups (i.e. high parental pressure and low parental pressure). Students with high 
parental pressure were found to be in the least stress among three groups and students with low parental pressure were more stressed as compared to students with high parental pressure but were less stressed are compared to students with moderate parental pressure. Hence hypothesis, "Medical aspirants with high parental pressure feel high stress compared to those with low parental pressure" also not get accepted.

Table 8: Mapping overall stress and parental pressure for a qualifying exam

\begin{tabular}{|c|c|c|c|c|c|c|}
\hline & & & & & & \\
\hline Parental Pressure & $\mathbf{N}$ & Mean & SD & $\mathbf{F}$ & df & Result \\
\hline High & 6 & 9.00 & 5.66 & \multirow{3}{*}{4.23} & \multirow{3}{*}{ 2. 93} & \multirow{3}{*}{$*$} \\
\hline Moderate & 21 & 16.19 & 7.16 & & & \\
\hline Low & 69 & 13.58 & 4.98 & & & \\
\hline
\end{tabular}

SD- standard Deviation df- degree of freedom

Graph 3: Mapping overall stress and parental pressure for the qualifying exam

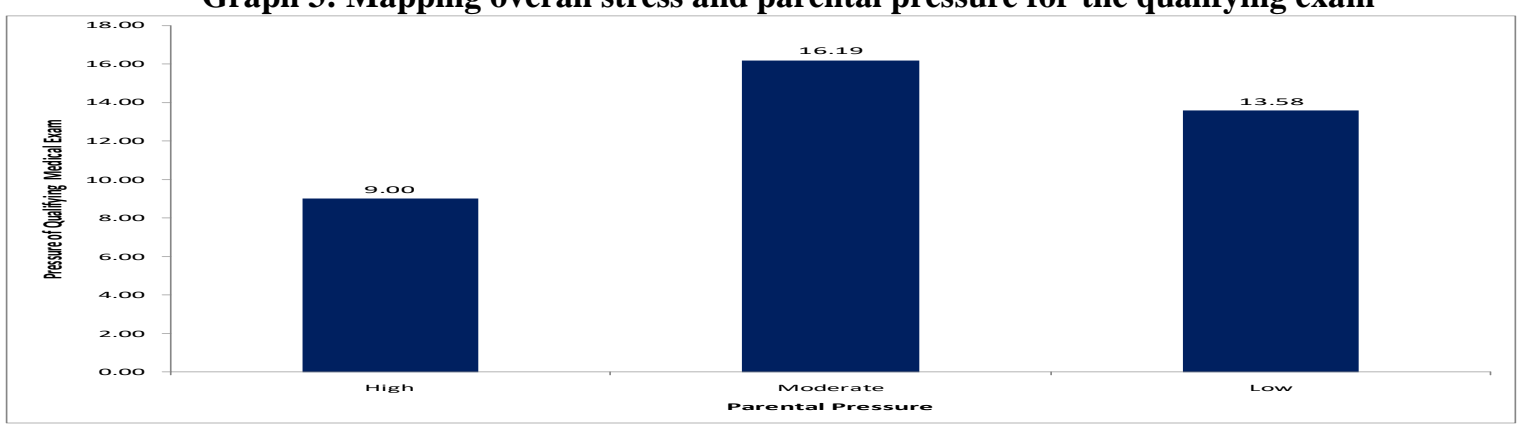

\section{Discussion}

The results of this study on medical aspirants showed that against the first hypothesis the majority of aspirants chose medicine on their own will and not under any pressure from parents. Many types of research proved that parental influence is too high on Indian children in choosing their career because they are the one to provide financial assistance to their kids throughout their study unlike West (Daraei, 2013). Studies were done on Kota suicide case by TISS and many other researchers independently also found out that students feel stressed due to family expectations and psychological pressure (Prajapati\& Singh, 2015). These results may be affected by the time of conducting the research. As mentioned above November 2018 was almost midterm as NEET 2019 was scheduled in May 2019. Admissions for that term happened in March-April 2018 and the majority of students who had come to Kota under any sort of family pressure have already left before November. This was confirmed by taking personal interviews of hostel owners Colonel Pushpendra Singh of Army Residency, Radhey Pratap Singh of Rising Star Residency, and Siddharth Rathore of Colonel's Residency. Colonel Pushpendra Singh shared that many students have left their hostels and went back to their homes after one or two months of coaching classes due to adaptability issues which include homesickness, academic pressure, insecurity etc. Hostel managers Kuldeep Kaur, Rakesh Kumar, and Sarika of various hostels shared that the cases of depression and anxiety due to stress among the students are more during the start of the session or towards the end of the academic session in the coaching institutes. Adjustment problems and homesickness are few of the reasons for the stress in the starting while fear of failure in the entrance exam or embarrassment of not doing well in the tests is few of the reasons for depression towards the end of the academic session.

There might be other reasons as well for the results not matching with the previous studies done by the researchers and TISS. This study was carried out during Diwali holidays and Allen Career Institute had declared almost a week-long holidays break for Diwali because of which students have gone home and there were chances that students who had been left behind were the one which lives far away from Kota and had travel time issues which are shown by the table 3 where most of the sample students were from Bihar, Orrisa, Chhattisgarh and far-flung states. Apart from that, there could be a chance that those who were left behind were determined for the medical entrance and don't want to waste their time by going home in holidays. That is why results shown in table 6 read as students aspired for the medical profession out of their own will. 
There might be chances where students who felt parental pressure but still preparing for the entrance exams have gone to their home towns for Diwali break, therefore, wasn't able to be part of this survey. Even the bigger sample size might have had given slightly different results.

The real picture of this kind of study would come if it is being done at the start of the session i.e. March-April. Same applies for results of stress level which says students with low parental pressure who were in majority compared to those with high parental pressure, which supports the result of the first hypothesis that they have chosen medicine out of their own will thus have least parental pressure. Now with this, there must be least overall pressure too on them, but the results don't show that. It shows students with high parental pressure has the least overall pressure. This is something to be studied further. But one result which shows males feel more stress or pressure compared to women aspirants indirectly says that boys in adolescent age face more stress due to expectations from family and parents to settle down (Daraei, 2013) due to patriarchal societal set up which says men need to be a breadwinner for the family.

\section{Limitations}

If the time of the study would have been different i.e. March-April at the start of the new session in the coaching institute then there might be a possibility of getting results in sync with the previous studies about parental influence on making a career choice and indirectly on stress levels. Bigger sample size would have also made the scene different. Taking parents opinion on this topic can also throw some more light and bring upon a clear picture of the whole scenario. Personal interviews of coaching mentors and psychologists appointed in coaching institutes would have also thrown some more light on the issue.

\section{Conclusions}

Adolescent children choosing medicine as a career out of their own will against what was hypothesised. Boys are more stressed during this age due to expectations for settled career reasons might be parents, family and society at large. Medical aspirants with low parental pressure feel low stress compared to those with moderate parental pressure. This somehow doesn't seem to be in line with the previous studies on similar topics but could have been further explored to find out whether the scenario is changing for good in Kota or there are some other reasons behind the derived results.

\section{Future Research}

If we talk about this study, the variation in mapping stress experienced by medical aspirants with the level of parental pressure could be further studied with a changed time of study and sample size. But if we talk about Kota and the environment there, studies could have been performed on the initiatives taken by the district administration, coaching institutes and the State Government to help students to express more about their fears and apprehensions and handle stress. Lot of efforts have been done by various entities in Kota like counselling of students by NGOs like 'Hope' and in-house counsellors appointed by coaching institutes as a part of compliance to administrative orders (TNN, 2018, December 29), recreational activities for the students organized by joint efforts of coaching institutes and district administration ("The career coaches", 2018), Diwali breaks given to students which rarely used to happen in past, etc. In fact, district administration along with the spiritual organizations like Isha Foundation (Khan, 2016, March 6) and Art of Living(PaGaLGuY, 2016, July 13) are organizing yoga classes in the coaching institutes for the students to make them psychologically strong by practising yoga and breathing exercises. These efforts and their impact need to be studied. Are they enough or more to be done? Studies to be conducted describing parental dilemma and their aspirational journey. Stress amongst adolescent students is not an issue related to Kota only, it is prevalent across India and needs to be addressed to have mentally healthy future generations.

\section{References}

[1]. Abdulghani, H. M., AlKanhal, A. A., Mahmoud, E. S., G.Ponnamperuma, G., \& Alfaris, E. A. (2011). Stress and Its Effects on Medical Students: A Cross-sectional Study at a College of Medicine in Saudi Arabia. Journal of Health, Population and Nutrition, 29(5), 516-522. Retrieved from http://www.jstor.org/stable/23500244

[2]. Bedewy, D., \& Gabriel, A. (2015). Examining perceptions of academic stress and its sources among university students: The Perception of Academic Stress Scale. Health Psychology Open, (July-December), 1-9. doi:10.1177/2055102915596714

[3]. Chhapia, H. (2018, January 28). Drugs, sex, stress: Why Kota may be a bad place for your child. The Times of India. Retrieved from https://timesofindia.indiatimes.com/india/drugs-sex-stress-why-kota-may-be-a-bad-placefor-your-child/articleshow/62677425.cms 
[4]. Daraei, M. (2013). Social Correlates of Psychological Well-Being Among Undergraduate Students in Mysore City. Social Indicators Research, 114(2), 567-590. Retrieved from http://www.jstor.org/stable/24720264

[5]. Khan, S. (2016, March 6). Kota goes the yoga way to counter stress among students. The Times of India. Retrieved from https://timesofindia.indiatimes.com/home/education/news/Kota-goes-the-yoga-way-to-counter-stress-amongstudents/articleshow/51273021.cms

[6]. Madhyastha, S., Latha, K., \& Kamath, A. (2014). Stress, Coping and Gender Differences in Third Year Medical Students. Journal of Health Management, 16(2), 315-326. doi:10.1177/0972063414526124

[7]. Malatskey, L., Willis, T. A., \& Rudolf, M. C. (2017). Leading Healthy Lives: Lifestyle Medicine for Medical Students. American Journal of Lifestyle Medicine, 20(10), 1-7. doi:10.1177/1559827616689041

[8]. NEET-UG / AIIMS Coaching. (n.d). Retrieved from https://www.allen.ac.in/neet-ug-aiims-coaching.asp

[9]. PaGaLGuY. (2016, July 13). Kota takes steps to address student stress levels. The Art of Living. Retrieved from https://www.artofliving.org/in-en/kota-steps-address-student-stress-levels

[10].Prajapati, N., \& Singh, K. (2015). Kota Coaching Institutions-A Stressor For Competitive Students (With Special Reference To Kota Coaching Institutions). Arts \& Education International Research Journal, 2(1), 10-18. Retrieved from http://www.imrfjournals.in/pdf/MATHS/AEIRJ-VOLUME-2-ISSUE-1-2015/3.pdf

[11].Panchu, P., Bahuleyan, B., \& Vijayan, V. (2017). An Analysis of the Factors Leading to Stress in Indian Medical Students. International Journal of Clinical and Experimental Physiology, 4(1),48-50. doi: 10.4103/ijcep.ijcep_58_16

[12].Sarkar, S., Gupta, R., \& Menon, V. (2017). A Systematic Review of Depression, Anxiety, and Stress among Medical Students in India. Journal of Mental Health and Human Behaviour, 22(2), 88-96. doi:10.4103/jmhhb.jmhhb_20_17

[13]. The career coaches. (2018, February 23). India Today. Retrieved from https://www.indiatoday.in/magazine/supplement/story/20180305-training-centres-career-1176315-2018-02-23

[14].TNN. (2018, December 29). Kota collector reviews norms for coaching students. The Times of India. Retrieved from

https://timesofindia.indiatimes.com/city/jaipur/kota-collector-reviews-norms-for-coachingstudents/articleshow/67294197.cms

[15].Wu, D., Yang, T., Rockett, I. R., Yu, L., Peng, S., \& Jiang, S. (2018). Uncertainty stress, social capital, and suicidal ideation among Chinese medical students: Findings from a 22-university survey. Journal of Health Psychology, 1-12. doi:10.1177/1359105318805820 